\title{
REFLEXÕES ACERCA DA HISTÓRIA E DO OFÍCIO DO HISTORIADOR
}

\section{Reflections on history and on the historian's profession}

\author{
Prof. Dr. João Batista Bitencourt (UFMA) \\ Docente da Graduação e da Pós-Graduação em História (PPGHIS) \\ Universidade Federal do Maranhão \\ Pós-Doutorado na Universidade Federal do Rio Grande do Sul (UFRGS) \\ ORCID: https://orcid.org/0000-0002-4640-8963 \\ E-mail: bitencourt.jb@gmail.com
}

Recebido em: 20/06/2020

Aprovado em: 21/09/2020

\begin{abstract}
Resumo: Partindo do fragmento de um diálogo do filme Seven: os sete crimes capitais e da referência a duas imagens bem conhecidas dos historiadores, o presente artigo busca refletir sobre as maneiras de fazer próprias do historiador e a constituição da história como disciplina, sua institucionalização, por uma observação sobre a Escola Metódica francesa. Aborda alguns elementos de composição do saber histórico - acontecimento, tempo e narrativa -, compreendendo como tais elementos se apresentam no mito de criação, na imagem de Clio, e na sociedade moderna, através da interpretação de Walter Benjamin do Angelus Novus. Busca ainda pensar como implicações do presente, do momento em que o passado é evocado, refletem na prática do historiador, no seu entendimento da história e, por conseguinte, na representação que constrói sobre determinada realidade pretérita.
\end{abstract}

Palavras-chave: conhecimento histórico; história da historiografia; operação historiográfica.

Abstract: From a piece of dialogue from Se7en (1995) and from the reference of two wellknown images to historians, this article aims to think over the ways that historians write history and the constitution of History as a discipline, its institutionalization, and an observation from French Methodic School. Also, it approaches some compositional elements of historical knowledge - event, time and narrative -, understanding how these elements are present in the creation myth, in the image of Clio, and in modern society, through the interpretation of Angelus Novus by Walter Benjamin. In addition, this paper looks on how implications from the present, at the moment in which the past is evoked, reflect in the practice of the historian, in his understanding of history and, therefore, the representation that is conjured about certain preterit reality.

Keywords: historical knowledge; history of historiography; historiographical operation. 


\title{
Transitório náufrago no tempo
}

Em Seven: os sete crimes capitais, suspense policial do diretor David Fincher (USA - 1995), veem-se dois detetives empenhados em solucionar uma série de crimes, cujo autor agia na intenção de desafiá-los. A certa altura da trama, Mills, um jovem investigador, empolgado por encontrar uma boa pista, tem seu entusiasmo contido por seu parceiro, o experiente Somerset. Travam eles o seguinte diálogo:

\begin{abstract}
Detetive Mills: Então o que é que estamos fazendo?
Detetive Somerset: Juntando peças. Estamos recolhendo provas, tirando fotos, pegando amostras, anotando tudo...

Estamos organizando tudo e guardando. Há uma chance remota de que seja necessário no tribunal.

Estamos apanhando diamantes numa ilha deserta e guardando para o caso de sermos resgatados.
\end{abstract}

Tal diálogo expressa maneiras de fazer que se aproximam e servem para pensar sobre o ofício do historiador. As relações entre ações que envolvem o trabalho de detetives e historiadores foram cotejadas por Carlo Ginzburg, ao delinear o "paradigma indiciário", que consiste na pesquisa e interpretação históricas centradas nos pormenores, nos dados marginais, nos indícios reveladores, capazes de levar o historiador a um diagnóstico, um conhecimento conjectural do passado, partindo, então, de uma investigação decifrativa (GINZBURG 1991, 1990).

Penso que as maneiras de fazer a história também caminham neste sentido. Seguir pistas, procurar trilhas, inquirir evidências, investigar e anotar o que encontrar nessa busca, para em seguida, utilizar nas representações de um acontecimento, de um tema e de um problema. Cruzar várias informações, vários fios de uma tessitura social, para montar uma conjectura acerca de um passado. Porém, assim como os detetives que partiram de um problema, solucionar crimes, também o historiador parte das inquietações que o afligem em sua contemporaneidade, projetando-se com esses desassossegos para outro tempo, indo atrás de uma intriga, construindo a representação de uma realidade anterior. ${ }^{1}$ Esta reapresentação da realidade, no entanto, não é o resgate do passado tal como ele ocorreu, é uma imagem que converge para uma convenção de veracidade, encarada como uma construção possível; é a montagem de um enredo que separa, classifica, escolhe o que serve, o que tem pertinência, o que se ajusta à estrutura deste enredo e ao tipo de narrativa dada ao texto. Há, pois, nesse trabalho, uma série de escolhas feitas pelo historiador para que as evidências utilizadas respondam às suas

\footnotetext{
${ }^{1}$ Cabe salientar que a própria ideia de realidade histórica foi repensada com os novos objetos e as novas abordagens da disciplina, a história tem se voltado para as circularidades culturais, os imaginários sociais, as construções de identidade, a própria busca por uma história dos vencidos fez com que se expandissem as pesquisas para os projetos não realizados, os não vitoriosos. Realidade histórica não é mais o sinônimo de concretude como se fez crer durante muito tempo. O recente direcionamento da história para o campo da cultura firmou ainda mais essa tendência, adentrando ao universo do pensado, imaginado, sentido. Atualmente, a realidade histórica pode ser, até mesmo, uma "mentira" como mostrou Hugh Trevor-Roper ao escrever sobre a invenção de uma cultura e tradição específicas das Terras Altas da Escócia (TREVOR-ROPER 1994).
} 
indagações. É nestas escolhas, nas questões que formula sobre determinada problemática e no tipo de narrativa por que opta para desenvolver o enredo e, inclusive, na própria opção por determinada problemática, que se pode encontrar as percepções e perspectivas de cada historiador sobre a história.

Vários historiadores, ainda que com divergências entre si, têm concordado em reconhecer a importância das realidades do presente e da imaginação criativa ao representar o passado. Para Roger Chartier, que faz uma síntese mais ponderada da questão, compreender em história consiste em buscar a decifração de uma intriga, a representação provável de uma realidade histórica. Contudo, esta representação é submetida às relações do próprio tempo em que é construída, assim como sua compreensão também se dá sob o controle da composição e ordenamento do próprio relato e da escolha do gênero narrativo. Segundo o autor, o trabalho historiográfico, atualmente, acha-se entre: "as representações manipuláveis hoje em dia e as práticas passadas que elas designam" (CHARTIER 1990, p. 86). Opiniões não tão conciliadoras são encontradas em Edward P. Thompson e Hayden White. Para o primeiro a história tem uma lógica própria com objeto e interpretação elásticos, com práticas múltiplas, que rejeita regras fixas e modelos estáticos. Um diálogo entre conceitos, hipóteses e evidências, "uma representação adequada (embora aproximativa)" (THOMPSON 1981, p. 54). Já o segundo vê apenas como formal a diferença entre o relato histórico e o ficcional. White estabelece as semelhanças entre estes tipos de relatos, atestando que toda a história carrega uma meta-história e que a interpretação historiográfica consiste na combinação expressa no texto, pela escolha do "modo de urdir o enredo" - estética, do "modo de explicação" - epistemológica e do "modo de implicação ideológica" - ética (WHITE 1994). ${ }^{2}$

Por outro viés, também Marc Bloch, contempla dimensões do presente no conhecimento histórico. Ao conceber a história como a ciência das mudanças no tempo, entende a contemporaneidade do historiador como ponto de partida e de chegada do seu ofício, já que seria papel da história a compreensão do presente pelo passado. Assim, uma cautelosa regressão caracterizaria seu método de trabalho, prudente ao ponto de não apagar as singularidades de outros tempos (BLOCH 2001). Pode-se pensar o passado como um estrangeiro, com língua e costumes que não nos são comuns, pois comunga de valores, crenças e percepções que necessariamente não nos alcançam. Caberia, então, ao historiador captar o sentido das coisas tal como um dia elas foram vivenciadas e apresentá-lo em seu presente, servindo de alteridade para a compreensão do mundo em que vive. Jörn Rüsen, ao conceber uma matriz disciplinar para a história, também entende o historiador partindo, e retornando, do presente. Nela a atualidade fomenta os interesses do historiador em suprir as carências de orientação advindas de mudanças temporais, os interesses transformados em problemáticas a serem investigadas, através de perspectivas de abordagem, e conferidos pela pesquisa empírica, retornam à atualidade, sob as formas de representação, com a função de orientação diante das carências que foram o ponto de partida (RÜSEN 2001).

\footnotetext{
${ }^{2}$ Em trabalho recente, no qual aborda um paralelo entre "passado prático" e "passado histórico", Hayden White afirma que teve a ousadia, e que talvez tenha sido mal compreendido, em sugerir não haver grande oposição entre a escrita literária e a escrita histórica. E, ressalta a importância da forma ao empregar sentido ao conteúdo (WHITE 2014, p. 19).
} 
Voltando ao diálogo que serve de fio condutor, tal como o detetive Somerset demonstra que nem todas as pistas seguidas levarão à solução do caso investigado, muitas vezes uma pista leva a outra, o historiador também recolhe um grande número de evidências e mesmo já partindo com uma intencionalidade, nem todas elas se enquadram em sua representação, tornando-se inconsistentes à interpretação ou à abordagem, inadequadas à narrativa do enredo ou dispensáveis ao tipo de questionamentos que faz a uma época. Igualmente como na fala do detetive, tem o historiador sua ilha deserta, um tema-problema em um determinado tempo, nela recolhe diamantes, as evidências, e provavelmente escolhe aqueles que pensa ter maior valor na pretensão de sair da ilha; o que atesta ter, ele, uma compreensão do mundo fora dela e com este mundo estar interagindo. O lugar social do historiador e suas perspectivas historiográficas fomentam suas inquietações, levando-o a fazer uma e não outra indagação a uma época, que para respondê-la ele escolhe, seleciona, separa, classifica, reagrupa evidências. Segundo Michel de Certeau,

em história, tudo começa com o gesto de separar, de reunir, de transformar em "documentos" certos objetos distribuídos de outra maneira. Esta nova distribuição cultural é o primeiro trabalho. Na realidade, ela consiste em produzir tais documentos, pelo simples fato de recopiar, transcrever ou fotografar estes objetos mudando ao mesmo tempo o seu lugar e seu estatuto (CERTEAU 1982, p. 81). (grifos do autor)

Este lugar social que direciona a prática historiográfica é, por assim dizer, multifacetado, desdobra-se em dimensões econômico-culturais, político-geracionais e, igualmente, institucionais. A interpretação histórica liga-se a um "sistema de referências" emanado de um lugar de produção, que busca conjurar perigos e desvios, conter excessos, coibir dissonâncias e consagrar enquadramentos (CERTEAU 1982, p. 65-77). Assim, mesmo que solitário em uma ilha deserta, o náufrago temporário carregou consigo uma sedimentação cultural anterior do lugar de que partiu, com todos os "conflitos do seu presente". Como o lugar de partida é igualmente o de retorno, tanto os diamantes recolhidos como a visão da ilha construída a partir deles, tendem a circunscrever-se ao que nele é permitido e elogiável.

Se é possível encontrar na metáfora da ilha deserta uma imagem pertinente do que sejam as maneiras de fazer do historiador, pode-se também por meio dela refletir sobre a própria produção, o conteúdo historiográfico resultante de seu trabalho, a história. Acredito, então, que o historiador não deva ser um eterno náufrago; ao estar na ilha deserta, está ele também pensando sobre o seu mundo, aliás, creio que, já parta para ela com esta perspectiva. Em outras palavras, acredito que uma produção histórica seja, também, um instrumento de reflexão da atualidade. Ao voltar da ilha deserta e construir uma imagem dela com os diamantes escolhidos, o historiador estabelece ligações, sua análise interage com sua contemporaneidade e, até mesmo, ouso dizer, nela busca interferir. Uma vez que ao reportar-se para outra época o historiador carrega suas preocupações presentes e, ainda que de forma inconsciente, acaba por esboçar projeções de futuro. Contudo, esta compreensão não é aquela que acredita encontrar na evolução do passado a explicação para o presente e o caminho para o futuro, como se a trajetória dos acontecimentos se desse em uma sequência de causa e efeito, dispensando os acasos e os refluxos. A qual respalda uma objetividade história, como se o passado que figura na história não esteja submetido aos jogos de interesses do momento da própria escrita. 
Se a história é a reapresentação de uma realidade anterior que só ocorre enquanto discurso presente, logo esse passado novamente apresentado sofre interferências do momento em que é evocado. Daí a ideia de representação, desenvolvida por Roger CHARTIER (1990, 2002, 2011), de algo que se coloca no lugar de outro, de uma presença que cobre uma ausência, que faz o papel de. Como o passado não mais existe, uma imagem resultante do trabalho do historiador toma o seu lugar. Mas o trabalho de construção dessa imagem está submetido aos jogos de interesses e percepções do ambiente que a constrói. Ou seja, há no trabalho do historiador uma série de escolhas que se mostram desde o momento da opção por estudar um determinado tema e denotam as perspectivas e posicionamentos do historiador sobre a história. Do lugar social do pesquisador e sua visão de mundo ao seu entendimento teórico e metodológico da história, muitas escolhas estarão a acoplar-se à sua abordagem e a interferir na compreensão da realidade anterior estudada.

O historiador é então um mestre da narrativa que, munido de teoria de análise e método crítico investigativo, constrói uma visão da ilha deserta com os diamantes que nela selecionou. Não é a ilha em sua autenticidade, mas uma representação dela que se tem verdadeira enquanto tal.

\section{De poética à disciplina}

Conta a mitologia grega que Zeus uniu-se a Mnemósine, a memória, durante nove noites, e dessa união nasceram nove musas. As musas, relata Hesíodo, alegravam o Olimpo "traduzindo em sons e palavras todos os grandiosos eventos do princípio", assim como desvelavam "as coisas presentes, as coisas futuras e as coisas passadas". Elas também abriam aos homens o caminho do conhecimento; ao introduzi-los nos segredos das coisas, davam aos homens a capacidade de pensar seu presente, planejar seu futuro e, por que não dizer, construir seu passado. Contudo, diferentemente dos deuses, elas não se revelavam a todos, escolhiam seus favoritos, também não desapareceram com o Olimpo, continuaram como uma presença invisível, como inspiração aos humanos formuladores de discursos. A história é simbolizada por uma dessas musas, Clio, aquela que celebra e preside a evocação do passado (HESÍODO apud NARDINI 1982, p. 99-103).

$\mathrm{Na}$ versão mitológica, a história é então filha do poder com a memória. Antídoto do esquecimento, é a memória a responsável pela identificação, ela diz o que somos e quem somos. Sem memória não temos passado nem identidade, não nos localizamos no mundo social e não compartilharíamos a herança social e cultural da humanidade. Seria como ter que reinventar a roda a cada dia. Parece que, desse modo, a história pode ser pensada como o poder de definir ou direcionar a memória coletiva. Pois, diferentemente da mãe que tem suas próprias regras de rememoração e esquecimento, a história estaria mais facilmente submetida aos controles do poder. Evidentemente, não se deve com isso supervalorizar o papel da história diante da memória; sabe-se que a segunda é imensamente maior, abarcando a primeira inclusive. Mas não devemos esquecer as relações de interação de ambas; a história interfere na memória na medida em que oferece um conteúdo pronto e acabado, cristalizado, ao passo que a memória pode novamente flexionar esse mesmo conteúdo com a sua lógica de lembrança e 
esquecimento, seleção que escapa à consciência, que articula não somente o momento da reminiscência, mas também todo um antes e um depois, que têm interferência na rememoração. Contudo, deve-se reconhecer igualmente que a filha na sociedade moderna parece ter suplantado a mãe. Nas palavras de Krzystof POMIAN (1999, p. 263), temos assistido a um deslizamento de ênfase "da história, parte da memória, à memória, objeto da história". A aceleração da vida moderna e o "dever da mudança" distanciaram a existência humana do ritmo marcado pelo que foi antigamente; não mais vivemos uma sociedade pautada por uma memória intocada, tradicional, pois se assim fosse, não haveria necessidade de guardar suportes materiais de recordação (NORA, 1993, p. 8-9).

O avanço tecnológico na área da comunicação tem nos transformado na sociedade da informação. Herdeira da sociedade industrial do século XIX, a sociedade da informação desenrola-se na mesma dinâmica de inovações que aquela, com o acelerado compasso de destruição e construção que caracteriza a modernidade. Assim como naquele mundo a ferrovia era símbolo da expansão/diminuição da terra, visto que sua velocidade fazia com que lugares remotos se tornassem acessíveis em tempos recordes, a internet atualmente proporciona comunicação on-line, interligando o mundo em "tempo-real". Nesse mundo em que a informação circula em cadência veloz, somos bombardeados diariamente com novos conhecimentos que negam valores e saberes anteriormente consensuais. Essa situação tem o seu avesso. É justamente no momento de intensa veiculação de informação que surgem o desejo e a necessidade de pessoas, instituições, cidades, etc. não perderem o conhecimento de si diante do turbilhão de novidades. Nunca se viu tanta velocidade na divulgação de informação, porém, igualmente, nunca se observou tanta vontade em construir museus, arquivos, memoriais entre outros "lugares de memória", capazes de perpetuar, frente à lógica da destruição, a lembrança de um povo, de uma instituição, de um lugar. Vivemos na sociedade da inovação e essa relação com o futuro, com o novo, com o "de ponta", produz um desejo de história. A velocidade na alteração do mundo cria o medo de se perder o elo com o passado e, desse modo, a própria identidade. Observa-se, assim, o peso da importância transferido à musa.

Nas ilustrações mais recorrentes, Clio aparece sempre adornada de uma coroa de louros e carrega uma trombeta e um livro. Quais sentidos pode-se apreender desses adereços? O simbolismo da coroa de louros é bastante conhecido; trata-se de uma atribuição de distinção, glorificação e honra. É premiação ao vencedor, àquele que tem êxito. A trombeta está ligada à fama, ao anúncio retumbante. Dá sucesso, visibilidade, estabelece a notoriedade. Já o livro lembra o registro que guarda e eterniza, impõe-se à lógica do esquecimento da memória. A história, assim, eternizava, dava fama e destacava os vencedores, uma vez que cumpria o papel de fornecer exemplos morais, como os heróis defensores das cidades.

Clio não é filha única, ela nasce juntamente com oito irmãs que, assim como ela, tinham o dom de traduzir em sons e palavras os eventos grandiosos. Clio é, desse modo, um campo da retórica, da arte de contar. Sua singularidade está naquilo que narra, seus eventos não são seus contemporâneos, são pretéritos. A história é então narrativa posterior, discurso sobre outro tempo, relato de um acontecimento anterior a si, uma poética que guarda singularidades perante outras. Nesse sentido, impõem-se três questões fundamentais à lógica desse saber: acontecimento, tempo e narrativa. A história é uma apresentação de um dado evento passado que só é possível por meio de um relato formulado no presente. Isto é, no momento da escrita. Em sua Poética, 
Aristóteles já distinguia do poeta o historiador por algo mais que a forma da escrita. Segundo o filósofo grego,

com efeito, não diferem o historiador e o poeta por escreverem verso ou prosa (pois que bem poderiam ser postas em verso as obras de Heródoto, e nem por isso deixariam de ser de história, se fosse em verso o que eram em prosa) diferem, sim, em que diz um as coisas que sucederam, e outro as que poderiam suceder (ARISTÓTELES apud SEVCENKO 1989, p. 21).

As palavras de Aristóteles levam à constatação de mais um importante elemento de composição do que é a história. $\mathrm{O}$ compromisso com a verdade ou a fidelidade com o ocorrido, a veracidade da realidade passada. Na lógica aristotélica, a poesia é superior à história. Por ter a vantagem da invenção, torna-se retoricamente mais perfeita. Como no mundo grego o valor do conhecimento não estava necessariamente em uma relação de verdadeiro ou falso, e sim de bem ou mal demonstrado, já que o que era bom era belo e o que era belo era bom (VALLS 2002, p. 15), o que também é posto em julgamento é a forma de enunciação. Ou seja, o valor do que se falava estava ligado à forma como se falava. Daí a superioridade da poesia, já que o inventar poderia proporcionar uma boa forma. Deve-se, no entanto, lembrar que a ideia de realidade histórica se transformou bastante e, nesse sentido, a história tem se voltado para o campo que Aristóteles creditava à poesia: o possível, e não somente o ocorrido.

Da Grécia antiga para os tempos modernos, uma alegoria da história que se tornou bastante conhecida através da interpretação de Walter Benjamin foi o Angelus Novus, quadro de Paul Klee. Com as asas prontas para o voo e na boca uma expressão que parece desejar o que os olhos arregalados contemplam, ele tem o olhar fixo em algo do qual parece se afastar. Benjamin aí viu uma imagem da história na modernidade:

\footnotetext{
o anjo da história deve parecer assim. Ele tem o rosto voltado para o passado. Onde diante de nós aparece uma série de eventos, ele vê uma catástrofe única, que sem cessar acumula escombros sobre escombros, arremessando-os diante dos seus pés. Ele bem que gostaria de poder parar, de acordar os mortos e de reconstruir o destruído. Mas uma tempestade sopra do paraíso, aninhando-se em suas asas, e ela é tão forte que ele não consegue mais cerrálas. Essa tempestade impele-o incessantemente para o futuro, ao qual ele dá as costas, enquanto o monte de escombros cresce ante ele até o céu. Aquilo que chamamos de progresso é essa tempestade (BENJAMIN 1985, p.158).
}

No olhar de Benjamin sobre o quadro de Klee, encontramos aqueles elementos de composição da história: os acontecimentos passados, as ruínas, os escombros que se acumulam incessantemente e que o atraem, mas dos quais ele é afastado; a narrativa, o desejo de ressuscitar os mortos e juntar os fragmentos; e o tempo, o lugar de onde olha que é posterior à existência do que já virou escombro, ruína. Mas há algo novo: a temporalidade, uma tempestade chamada progresso. Esse vendaval parte do paraíso, da origem, e avança impetuosamente ao futuro. É a temporalidade linear e progressiva que marcou a história e caracteriza o ritmo acelerado da vida moderna. Uma crença no progresso, um desejo de possuir o que está por vir, uma lógica de "autodestruição inovadora" lançaram a sociedade em uma constância de renovação e mudanças, sem lugar para o passado, a não ser como escombros, ruínas, ainda que muitas vezes 
contemporâneas. Pois nessa veloz dinâmica, como lembrou Marx, "tudo que é sólido se desmancha no ar" (BERMAN, 1992).

O contexto que gerou a renovação permanente pela lógica da máquina e do lucro, da ciência e do progresso, também gerou uma história nos mesmos moldes. $\mathrm{O}$ saber científico aplicado ao maquinismo, que produzia tecnologia, a fragmentação da produção e a crença na prosperidade futura podem ser observados no cientificismo do saber, na fragmentação do conhecimento e no positivismo da produção intelectual. Da musa ao anjo - e aqui se faz um grande salto -, a história passou de poética à disciplina, campo de saber institucionalizado. ${ }^{3}$

Escrevendo sobre o conceito de história, Walter BENJAMIN (1994, p. 229) assinalou que "a história é objeto de uma construção cujo lugar não é o tempo homogêneo e vazio, mas um tempo saturado de 'agoras'." Se um dos "agoras" é o compromisso com a realidade pretérita, a procura pelo sentido do acontecimento em seu tempo, um outro "agora" é sem dúvida as interferências do presente. Poderíamos então pensar a história em um tempo tridimensional; o tempo dos acontecimentos, o tempo do hoje, do momento em que é evocada, e o tempo da narrativa, que abarca os dois primeiros numa espécie de fusão de horizontes.

Há, então, na ação historiográfica diversas interferências do seu próprio tempo, do posicionamento político do historiador ao seu estilo narrativo, da disponibilidade de evidências à teoria que o embasa. Tal posicionamento atinge de forma certeira o estatuto de verdade que durante muito tempo a história ostentou, por aceitar que o relato histórico submete-se a ordenamentos que não são somente ditados pelo passado. Mas certamente é bastante difícil não concordar, pois não bastassem todas as mencionadas interferências do presente, que fazem da história uma representação do passado e não seu reflexo objetivo, o fato de trabalhar com evidências de outro tempo, em geral registros escritos, faz da história representação por representações, uma vez que os acontecimentos passados já nos chegam como relato, já uma descrição que igualmente sofreu o crivo de quem a redigiu.

Um dos "agoras" que interferem na visão sobre o passado diz respeito à perspectiva histórica resultante do alinhamento com determinada matriz historiográfica, ou teoria de análise, pois, como disciplina, a história constituiu regras, métodos, conceitos; maneiras de fazer próprias do campo do saber. Essas lógicas e práticas da história são também mutáveis, com escolas e arcabouços teóricos que se transformam no tempo e implicam alterações na compreensão e representação do passado. $\mathrm{Na}$ abertura da obra História e memória, Jacques Le Goff apresenta seis problemas para o conceito de história e o primeiro deles diz respeito justamente a essa relação entre os acontecimentos pretéritos e o arsenal analítico que os aborda:

que relações existem entre a história vivida, a história 'natural', senão 'objetiva', das sociedades humanas, e o esforço científico para descrever, pensar e explicar esta evolução, a ciência histórica? O afastamento de ambas tem, em especial, permitido a existência de uma disciplina ambígua: a filosofia da história. Desde o início do século, e sobretudo nos últimos vinte anos, vem se desenvolvendo um ramo da ciência histórica que estuda a

\footnotetext{
${ }^{3}$ Deve-se esclarecer que aqui se aborda a profissionalização por uma leitura da historiografia francesa, e isso se deve a algumas razões, entre elas o sucesso da historiografia francesa em termos mundiais e a sua forte influência sobre a produção historiográfica brasileira.
} 
evolução da própria ciência histórica no interior do desenvolvimento histórico global: a historiografia, ou história da história (LE GOFF 1994, p.7).

Dito de outro modo, o papel do profissional da história dilatou-se ao conhecimento do próprio movimento da história, uma procura por ela mesma, um entendimento de si própria que começa no século XIX com sua institucionalização. O final do século XIX é o momento em que na França ocorre a profissionalização da história; estabelece-se o campo de conhecimento que se institucionaliza. A disciplina história resulta de um consenso de comunidade, da consciência dos que fazem história, de que no que fazem compartilham de certo domínio, com determinadas práticas, métodos e fronteiras que os separam de outros domínios. Definir o papel, a função e os critérios do historiador, possibilitando a autonomia como campo intelectual e acadêmico ao estabelecer o que é e o que não é história, passou pela criação de rigorosos critérios de produção, uma profissionalização da história que decretava o fim do tempo de aventuras e de produções aleatórias de diferentes pesquisadores com seus próprios direcionamentos. Regras metodológicas passaram a traçar os caminhos da construção histórica, delimitando um campo de ação do historiador e sua relação com os demais ramos das ciências sociais. Constituía-se uma comunidade de ofício, que passou a trabalhar para sua afirmação, definindo um domínio e uma congregação de iguais que avaliava se certa produção estava ou não de acordo com as regras, práticas, métodos e objetos. Ou seja, se era história (REVEL 1989, p.13-41).

A divulgação de dois importantes textos denota dois momentos significativos no processo de oficialização da história: em 1876, o lançamento da Revue Historique, com o manifesto de Gabriel Monod, no qual afirma: "nosso século é o século da história", e em 1898, Introduction aux études historiques, de Charles-Victor Langlois e Charles Seignobos, um manual de regras aplicáveis à disciplina destinado à orientação dos estudantes. Entre esses dois textos e momentos confere-se a afirmação do trabalho de arquivo, da referência às fontes e da organização da produção, que caracterizam a Escola Metódica, vulgarmente conhecida como positivista. Os historiadores que dela participavam passaram a ocupar destacados postos, estando presentes na reforma universitária e nos postos das novas universidades. Também eram vistos na Sorbonne, no Collège de France, em gabinete ministerial, nos conselhos, na direção das grandes coleções e formulavam as obras e programas do ensino secundário e primário. Em suma, revestiam-se de grande poder (BOURDÉ e MARTIN 1983, p. 137-170).

Se a constituição de um campo de saber se dá por sua organização interna perante e sua distinção com outros, a irmandade dos historiadores profissionais, com seus espaços de afirmação e consagração, tem uma relação de explícito atrito com a sociologia. No início do século, o domínio da sociologia na academia francesa era bastante grande. A ciência social só existia no singular; era a sociologia, mais exatamente a durkheimiana, que via os historiadores com desprezo. $\mathrm{O}$ apego à política contada através de nomes próprios e fatos isolados, sem teoria ou análise conjuntural, apenas uma narrativa descritiva, era o olhar que a sociologia aplicava à história, comparando-a a uma compilação anedótica de curiosidades. A crítica que mais ecoou veio de François Simiand, que apontou e atacou "os ídolos da tribo dos historiadores", a saber: o apego aos fatos políticos; o peso dos indivíduos, com a ênfase nos chamados grandes homens; e a prisão cronológica, com a busca das origens (BURKE 1991, p. 21). 
O artigo de Simiand, de 1903, surge como uma resposta às confirmações do método histórico tradicional que Charles Seignobos reafirmava em Méthode historique appliquée aux sciences sociales (1901), no qual incluí nessa categoria quaisquer estudos dos fenômenos sociais. Porém, embora a sociologia apresentasse maior dinamismo na renovação da prática científica, ao contrário da história, que se ramificava pelo sistema acadêmico, era um tanto marginal no sistema universitário e no reconhecimento social (REVEL 1989, p. 19-21).

A história metódica é uma história de modelos, de exemplos positivos e negativos de conduta. A boa forma da musa deu lugar ao peso da mensagem passada. A retórica deixa de ser forma de conhecimento, pois a apresentação perde valor para a mensagem, impõe-se a ideia de verdadeiro ou falso, e com isso a importância da fonte e do método para chegar à verdade. Nessa relação de institucionalização da história vê-se a relação do poder com a memória social, para criar o senso de república e da importância de sua restauração. A Comuna de Paris, com seu papel relevante na memória do movimento operário e a forte repressão que sofreu, necessitava ser reelaborada na consciência popular; os historiadores aliados à política vigente trabalharam para firmar a ordem republicana. A República francesa procurava ocupar-se do sistema de ensino e, através da história, constituir uma memória nacional, o senso de educação cívica, como educação política. Surgem então os combates exemplares pela pátria e sua galeria de heróis. Constituir a aceitação da República e do papel do Estado e transmitir a concepção de tempo de progresso, possibilitando à população a ideia de transformação, criando um modo de pensar que compreendesse a evolução como fenômeno natural, estava no âmago daquele padrão historiográfico. Daí uma história linear-progressiva recheada de batalhas, repleta de grandes vultos e que partia do Estado.

Embora pareçam evidentes as relações dos metódicos com os interesses da República, afirmavam eles que professavam uma história científica e imparcial. Os métodos determinavam um tipo de ação que caracterizava a disciplina e uma forma de se desvencilhar de interações pessoais com o passado. Assim, encontra-se a importância do documento como expressão da verdade. Dentre eles, o destaque aos escritos e, nesses, a validade dos oficiais. Baseado nos documentos, com métodos rígidos e pouco apego à teoria, o historiador estava imune às distorções da verdade sobre o ocorrido. Neutro, ele apenas revelava o passado assim como ocorreu, uma história objetiva. Essa história, então, era a "rainha das ciências" e travava com as demais disciplinas uma relação de superioridade. Elas eram importantes, pois ajudavam como "ciências auxiliares" (GLÉNISSON 1979, 79-122).

\section{Refências Bibliográficas}

BENJAMIN, Walter. Magia e técnica, arte e política: obras escolhidas I. $7^{a}$ ed. São Paulo: Brasiliense, 1994 [1985].

BENJAMIN, Walter. Walter Benjamin. São Paulo: Ática, 1985.

BERMAN, Marshall. Tudo que é sólido desmancha no ar: a aventura da modernidade. $9^{\mathrm{a}}$ reimpressão. São Paulo: Companhia das Letras, 1992 [1986]. 
BLOCH, Marc. Apología da história ou o ofício do historiador. Rio de Janeiro: Zahar, 2001.

BOURDÉ, Guy e MARTIN, Hervé. Les écoles historiques. Paris: Seuil, 1983.

BURKE, Peter. A Revolução Francesa da historiografia: a Escola dos Annales, 19291989. São Paulo: UNESP, 1991.

CERTEAU, Michel. A escrita da história. Rio de Janeiro: Forense Universitária, 1982.

CHARTIER, Roger. O passado composto: relações entre filosofia e história. In: A história cultural: entre práticas e representações. Lisboa: Difel, 1990, p. 69-89.

À beira da falésia: a história entre certezas e inquietudes. Porto Alegre: UFRGS, 2002.

Defesa e ilustração da noção de Representação. Fronteiras, Dourados, MS, v. 13, n. 24, p. 15-29, jul./dez. 2011.

GINZBURG, Carlo. Chaves do mistério: Morelli, Freud e Sherlock Holmes. In: ECO, Umberto e SEBEOK, Thomas A. (Orgs.) O signo de três: Dupin, Holmes, Peirce. São Paulo: Perspectiva, 1991, p. 89-129.

GINZBURG, Carlo. Mitos, emblemas e sinais: Morfologia e história. São Paulo: Cia das Letras, 1990.

GLÉNISSON, Jean. Iniciação aos estudos históricos. 3a ed. São Paulo: Difel, 1979 [1977].

LE GOFF, Jacques. História e Memória. 3ª ed. Campinas: UNICAMP, 1994 [1992].

NARDINI, Bruno. Mitologia: o primeiro encontro. São Paulo: Círculo do livro, 1982.

NORA. Pierre. Entre memória e história: a problemática dos lugares. Projeto história. São Paulo, n. 10, p. 7-28. dez. 1993.

POMIAN, Krzysztof. Sur l'histoire. Paris: Gallimard, 1999.

REVEL, Jacques. A invenção da sociedade. Lisboa: Difel, 1989.

RÜSEN, Jörn. Razão histórica: teoria da história, fundamentos da ciência histórica. Brasília: UnB, 2001.

SEVCENKO, Nicolau. Literatura como missão: tensões sociais e criação cultural na Primeira República. $3^{\circ}$ ed. São Paulo: Brasiliense, 1989 [1983].

THOMPSON, Edward P. Intervalo: a lógica histórica. In: A miséria da teoria: ou um planetário de erros. Rio de Janeiro: Zahar, 1981, p. 47-62.

TREVOR-ROPER, Hugh. A invenção das tradições: a tradição das Terras Altas (Highlands) da Escócia. In: HOBSBAWM, Eric e RANGER, Terence (Orgs.) A invenção das tradições. Rio de Janeiro: Paz e Terra, 1994. p. 25-51.

VALLS, Álvaro L. M. Estudos de estética e filosofia da arte. Porto Alegre: UFRGS, 2002, p. 15.

WHITE, Hayden. A interpretação na história. In: Trópicos do discurso: ensaios sobre a crítica da cultura. São Paulo: EDUSP, 1994, p. 65-95.

The practical past. Evanston: Northwestern University Press, 2014. 